\title{
Characteristics of the Voltages between the Communication Lines and Ground Induced by the Adjacent Artificial High-Voltage or Current ELF Source
}

\author{
Sangmu Lee ${ }^{1,2} \cdot$ Munhwan Choi $^{1} \cdot$ Pyung-Dong Cho ${ }^{1} \cdot{\text { Changsoo } \text { Eun }^{2} \cdot \text { Yoon-Myoung Gimm }}^{3}$
}

\begin{abstract}
The measurements were performed to verify experimentally that the voltage arising on a telecommunication line by a power line is due to the induction phenomena because there has been an opinion that the arising voltage on a telecommunication line is not by induction, but by other causality. The voltage appeared on the telecommunication line by way of an electric field or magnetic field generated by the source apparatus that had been artificially made to provide intentional constant high-voltage or current in ELF, that is, $60 \mathrm{~Hz}$ as an emulated commercial power.
\end{abstract}

Key words : Induction Phenomena, Induction Voltage, Source Generator, Electromagnetic Field.

\section{Introduction}

The electromagnetic induction has been acknowledged by theory and experiments, especially Faraday's law, etc. Such an induction phenomenon has been applied for implementation to various things necessary and useful in mankind's life.

In the field of telecommunication, the power line, which generates an electromagnetic field, may interfere with transmission signals. The magnetic field generated by the power line gives rise to induced current in nearby communication lines. So, protection measures are taken according to legal provisions ${ }^{[1],[2]}$. The measures are carried out when the induced voltage calculated with the formulas provided by the national legal notice ${ }^{[2]}$ is equal to excess over the limited voltage prescribed in the technical regulation rule ${ }^{[1]}$.

But there has been a questionable point as to whether the voltage onto telecommunication cables by power line or electrified railway line is really caused by induction. We are used to measuring the induced voltage with the technical regulation notice method ${ }^{[3]}$. But there is an opinion that just a potential difference between the two points of the ground is measured by the method.

Having made an EMI source generator emulating the commercial power operating at $60 \mathrm{~Hz}$ as an ELF, we experimented with whether the voltage generated onto a telecommunication cable by a nearby power line is due to an induction.

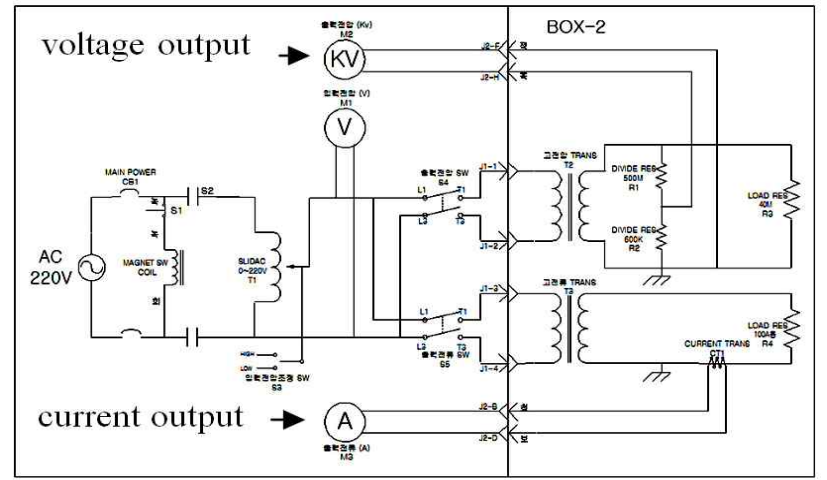

Fig. 1. Circuit diagram of source generator.

\section{II . Source Generation Circuit}

The high currents and voltages are generated by the artificially made apparatus from the $220 \mathrm{~V} / 60 \mathrm{~Hz}$ as the commercial power. The $220 \mathrm{~V}$ from the commercial power source is routed into the current- or voltage- generating section of the apparatus, and whether it can then be enhanced up to $15 \mathrm{kV}$ for high voltage or $100 \mathrm{~A}$ for high current. The circuit of the source generator is shown in Fig. 1.

\section{Experiment and Analysis}

\section{3-1 Measurement Configuration}

The installation configuration of components for mea-

Manuscript received June 29, 2009 ; revised October 1, 2009. (ID No. 20090629-026J)

${ }^{1}$ Korea Electronics and Telecommunications Research Institute, Daejeon, Korea.

${ }^{2}$ Information and Communication System, Chungnam National University, Daejeon, Korea.

${ }^{3}$ Dankook University and EMF Safety Inc., Gyeonggi, Korea. 
Induction

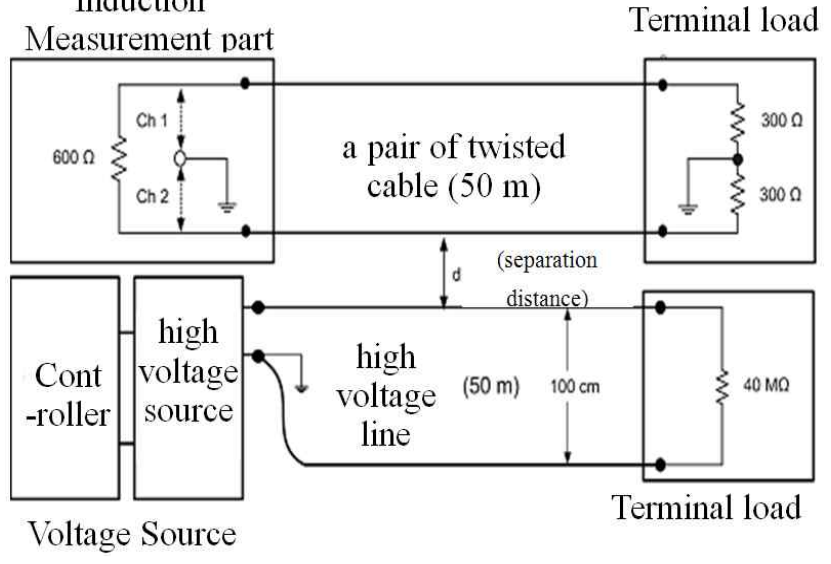

Fig. 2. The configuration of measurement.

surement is shown in Fig. 2. Basically, the distance between the feeder line and feedback line of the power line is set as $1 \mathrm{~m}$. And the distance between the communication line and the power line(this is separate distance: $d$ ) varies by $0.3 \mathrm{~m}$ from $0 \mathrm{~m}$ to $0.6 \mathrm{~m}$, which results in three measurements as to each distance change: measured at $0 \mathrm{~m}, 0.3 \mathrm{~m}, 0.6 \mathrm{~m}$. The parallelized length of both the communication line and power line is $50 \mathrm{~m}$. And for the high current source case, the terminal load is put as $0.2 \Omega$.

In addition, as the communication line is composed of a pair, which means having two core lines in a pair, two induced voltages(one is for $\mathrm{CH} 1$; the other for $\mathrm{CH} 2$ ) are measured to confirm that they are practically the same. This is an important factor because just a tiny difference of induced voltages between the core lines may give rise to noise voltage on the pair caused by the voltage difference between the core lines.

\section{3-2 Characteristics of the High-Voltage Source}

\section{3-2-1 0 m Separation Distance $(d=0)$}

The measured voltages induced onto communication cable are shown in Table 1, including peak-to-peak values and RMS values, and the CRO displays the waveform shown in Fig. 3 when the voltage source level is off(0 kV): Fig. $4 / 5 \mathrm{kV}$, Fig. $5 / 10 \mathrm{kV}$, Fig. $6 / 15 \mathrm{kV}$. The values of $\mathrm{CH} 1$ and $\mathrm{CH} 2$ are not completely the same, but show slightly different values.

We see that as by increasing the source voltage level, the induced voltage also increases proportionally, and that the default voltage exists when no source is pro$\operatorname{vided}(0 \mathrm{kV})$. It is presumed that there exists stray current in the ground or one that is caused by another unknown factor that can generate the voltage onto the cable. Some voltage can be usually checked between two
Table 1. Measured voltage at $d=0$.

\begin{tabular}{|c|c|c|c|c|}
\hline \multirow{2}{*}{$\begin{array}{c}\text { Source } \\
\text { voltage } \\
(\mathrm{rms})\end{array}$} & \multicolumn{2}{|c|}{ CRO-CH 1 } & \multicolumn{2}{c|}{ CRO-CH 2 } \\
\cline { 2 - 5 } & $V_{p-p}(\mathrm{~V})$ & $V_{\text {rms }}(\mathrm{mV})$ & $V_{p-p}(\mathrm{~V})$ & $V_{r m s}(\mathrm{mV})$ \\
\hline $0 \mathrm{kV}$ & 1.06 & 373 & 1.07 & 383 \\
\hline $5 \mathrm{kV}$ & 1.76 & 488 & 1.76 & 495 \\
\hline $10 \mathrm{kV}$ & 4.16 & 696 & 4.42 & 724 \\
\hline $15 \mathrm{kV}$ & 11.01 & 840 & 10.94 & 865 \\
\hline
\end{tabular}

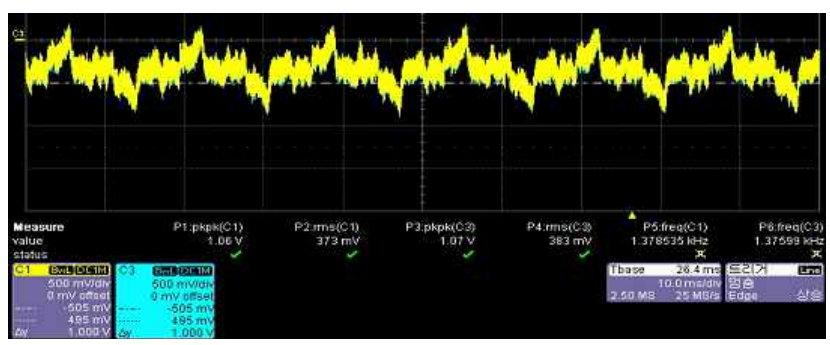

Fig. 3. Waveform at $d=0$ in $0 \mathrm{kV}(500 \mathrm{mV} / \mathrm{div}$, and 10.0 $\mathrm{ms} / \mathrm{div})$.

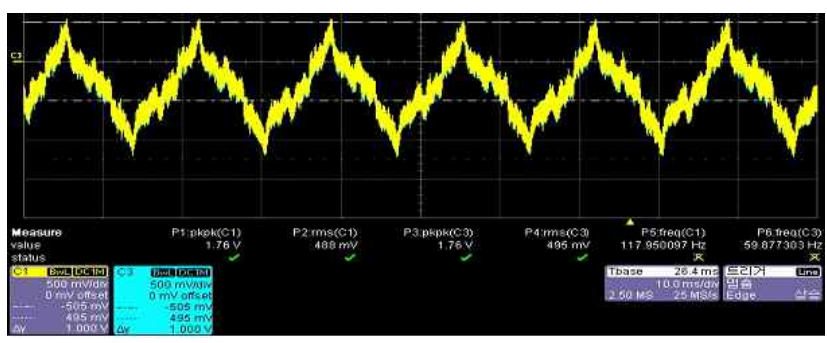

Fig. 4. Waveform at $d=0$ in $5 \mathrm{kV}(500 \mathrm{mV} / \mathrm{div}$, and 10.0 $\mathrm{ms} / \mathrm{div}$ ).

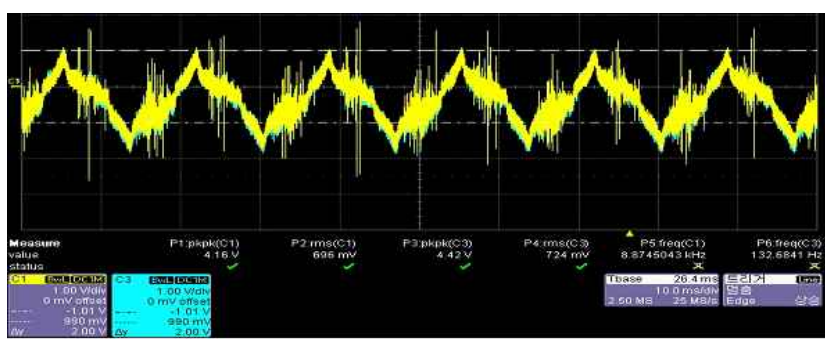

Fig. 5. Waveform at $d=0$ in $10 \mathrm{kV}(500 \mathrm{mV} / \mathrm{div}$, and 10.0 $\mathrm{ms} / \mathrm{div})$.

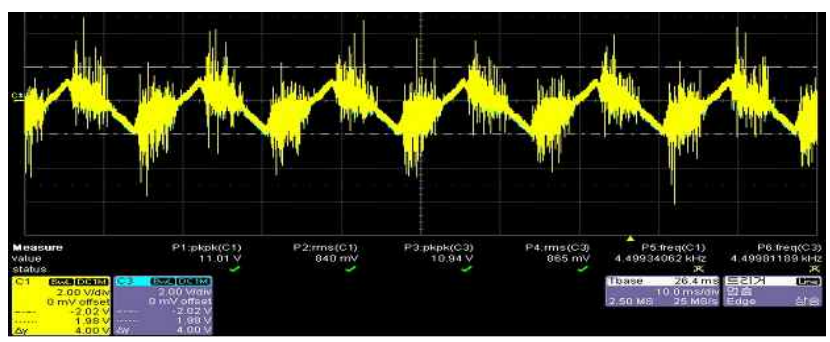

Fig. 6. Waveform at $d=0$ in $15 \mathrm{kV}(500 \mathrm{mV} / \mathrm{div}$, and 10.0 $\mathrm{ms} / \mathrm{div})$. 
LEE et al. : CHARACTERISTICS OF THE VOLTAGES BETWEEN THE COMMUNICATION LINES AND GROUND INDUCED BY…

points on the ground. This is due to the potential difference between those points which can exist by the current flowing in the ground.

\section{3-2-2 $0.3 \mathrm{~m}$ Separation Distance $(d=0.3 \mathrm{~m})$}

The measured voltages induced onto communication cable are shown in Table 2. CRO displays the waveform

Table 2. Measured voltage at $d=0.3 \mathrm{~m}$.

\begin{tabular}{|c|c|c|c|c|}
\hline \multirow{2}{*}{$\begin{array}{c}\text { Source } \\
\text { voltage } \\
(\mathrm{rms})\end{array}$} & \multicolumn{2}{|c|}{ CRO-CH 1 } & \multicolumn{2}{c|}{ CRO-CH 2 } \\
\cline { 2 - 5 } & $V_{p-p}(\mathrm{~V})$ & $V_{r m s}(\mathrm{mV})$ & $V_{p-p}(\mathrm{~V})$ & $V_{r m s}(\mathrm{mV})$ \\
\hline $0 \mathrm{kV}$ & 1.65 & 474 & 1.66 & 479 \\
\hline $5 \mathrm{kV}$ & 1.78 & 487 & 1.78 & 492 \\
\hline $10 \mathrm{kV}$ & 3.42 & 496 & 3.36 & 514 \\
\hline $15 \mathrm{kV}$ & 5.12 & 500 & 5.18 & 518 \\
\hline
\end{tabular}

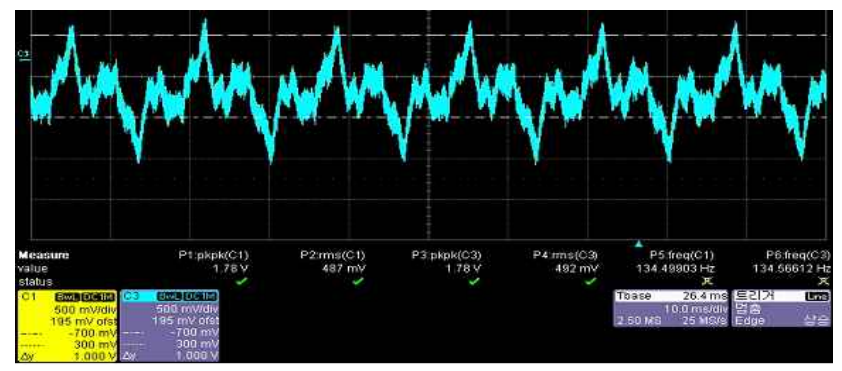

Fig. 7. Waveform at $d=0.3 \mathrm{~m}$ in $5 \mathrm{kV}(500 \mathrm{mV} / \mathrm{div}$, and $10.0 \mathrm{~ms} / \mathrm{div})$.

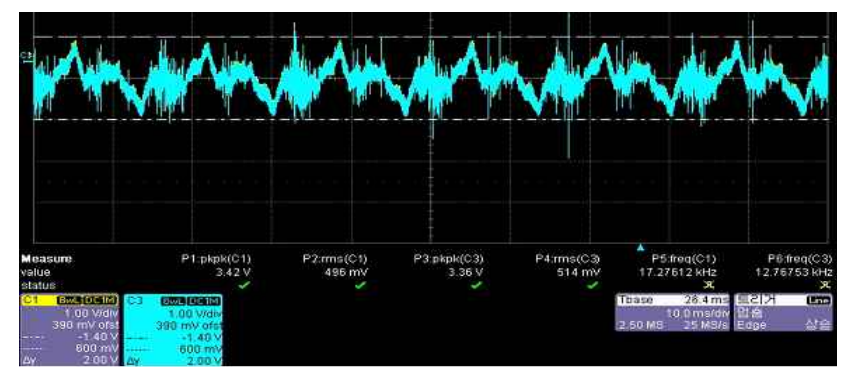

Fig. 8. Waveform at $d=0.3 \mathrm{~m}$ in $10 \mathrm{kV}(1.0 \mathrm{~V} / \mathrm{div}$, and $10.0 \mathrm{~ms} / \mathrm{div})$.

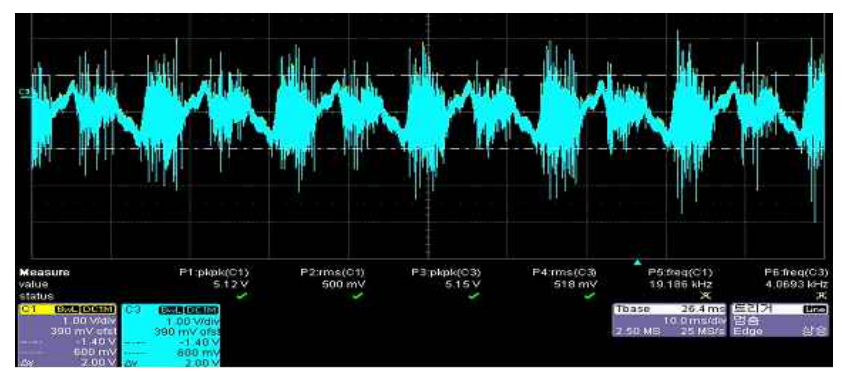

Fig. 9. Waveform at $d=0.3 \mathrm{~m}$ in $15 \mathrm{kV}(1.0 \mathrm{~V} / \mathrm{div}$, and $10.0 \mathrm{~ms} / \mathrm{div})$. shown in Fig. 7 when the voltage source level is $5 \mathrm{kV}$, Fig. 8/ $10 \mathrm{kV}$, Fig. 9/15 kV. The voltages of CH1 and $\mathrm{CH} 2$ are again not exactly the same, but slightly different. Also, by increasing the source voltage level, the induced voltage increases, but the degree of increase is smaller than the case of 0 distance.

\section{3-2-3 $0.6 \mathrm{~m}$ Separation Distance $(d=0.6 \mathrm{~m})$}

The measured voltages induced onto communication cable are shown in Table 3. CRO displays the waveform shown in Fig. 10 when the voltage source level is off $(0$ $\mathrm{kV}$ ), Fig. $11 / 5 \mathrm{kV}$, Fig. 12/ $10 \mathrm{kV}$, Fig. $13 / 15 \mathrm{kV}$.

$\mathrm{CH} 1$ and $\mathrm{CH} 2$ voltages are not the same exactly. At this time, the induced voltage rather decreased at $5 \mathrm{kV}$, and from the $10 \mathrm{kV}$ level, there has been a small voltage increase.

\section{3-2-4 Anaysis of Graph}

Fig. 14 is for $\mathrm{CH} 1$; Fig. 15 is for $\mathrm{CH} 2$. Although the Table 3. Measured voltage at $d=0.6 \mathrm{~m}$.

\begin{tabular}{|c|c|c|c|c|}
\hline \multirow{2}{*}{$\begin{array}{c}\text { Source } \\
\text { voltage } \\
(\mathrm{rms})\end{array}$} & \multicolumn{2}{|c|}{ CRO-CH 1 } & \multicolumn{2}{c|}{ CRO-CH 2 } \\
\cline { 2 - 5 } & $V_{p-p}(\mathrm{~V})$ & $V_{r m s}(\mathrm{mV})$ & $V_{p-p}(\mathrm{~V})$ & $V_{r m s}(\mathrm{mV})$ \\
\hline $0 \mathrm{kV}$ & 2.13 & 478 & 2.11 & 483 \\
\hline $5 \mathrm{kV}$ & 2.06 & 463 & 2.05 & 468 \\
\hline $10 \mathrm{kV}$ & 2.13 & 466 & 2.08 & 471 \\
\hline $15 \mathrm{kV}$ & 4.58 & 486 & 4.45 & 493 \\
\hline
\end{tabular}

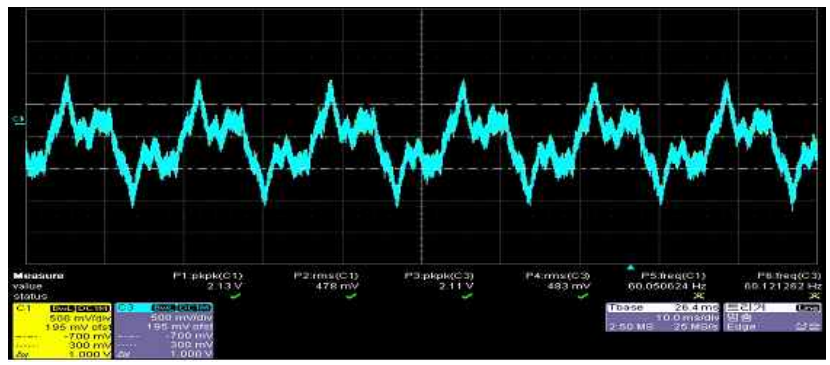

Fig. 10. Waveform at $d=0.6 \mathrm{~m}$ in $0 \mathrm{kV}(500 \mathrm{mV} / \mathrm{div}$, and $10.0 \mathrm{~ms} / \mathrm{div})$.

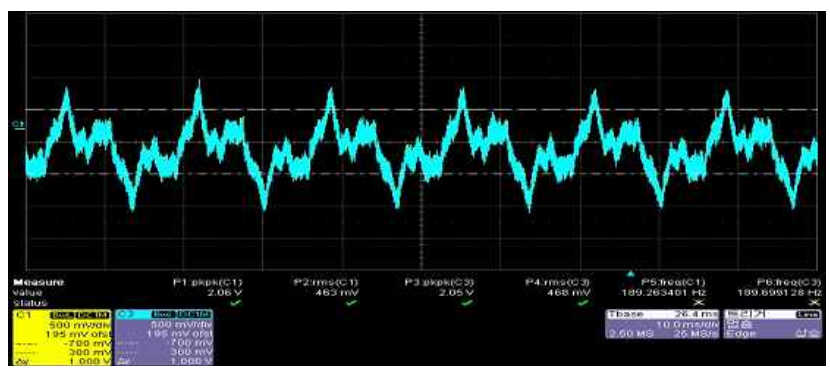

Fig. 11. Waveform at $d=0.6 \mathrm{~m}$ in $5 \mathrm{kV}(500 \mathrm{mV} / \mathrm{div}$, and $10.0 \mathrm{~ms} / \mathrm{div})$. 


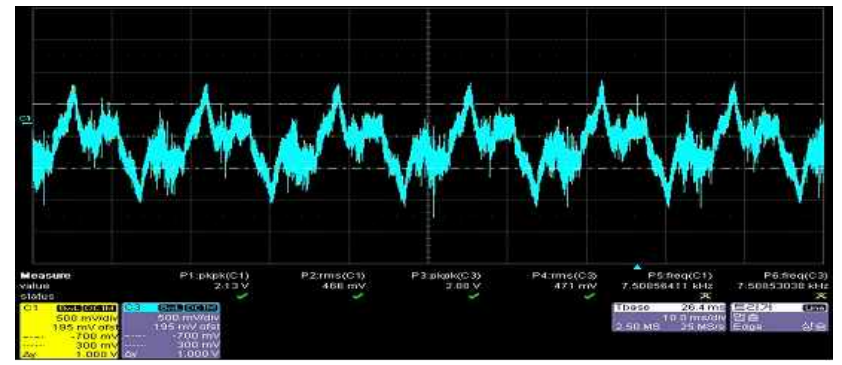

Fig. 12. Waveform at $d=0.6 \mathrm{~m}$ in $10 \mathrm{kV}(500 \mathrm{mV} / \mathrm{div}$, and $10.0 \mathrm{~ms} / \mathrm{div})$.

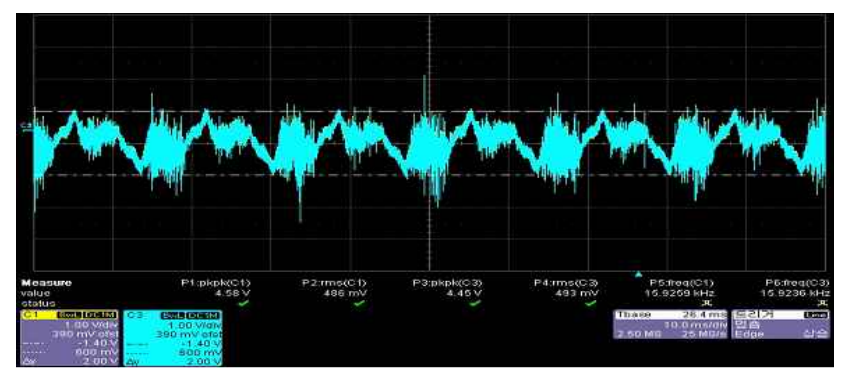

Fig. 13. Waveform at $d=0.6 \mathrm{~m}$ in $15 \mathrm{kV}(1.00 \mathrm{~V} / \mathrm{div}$, and $10.0 \mathrm{~ms} / \mathrm{div})$.

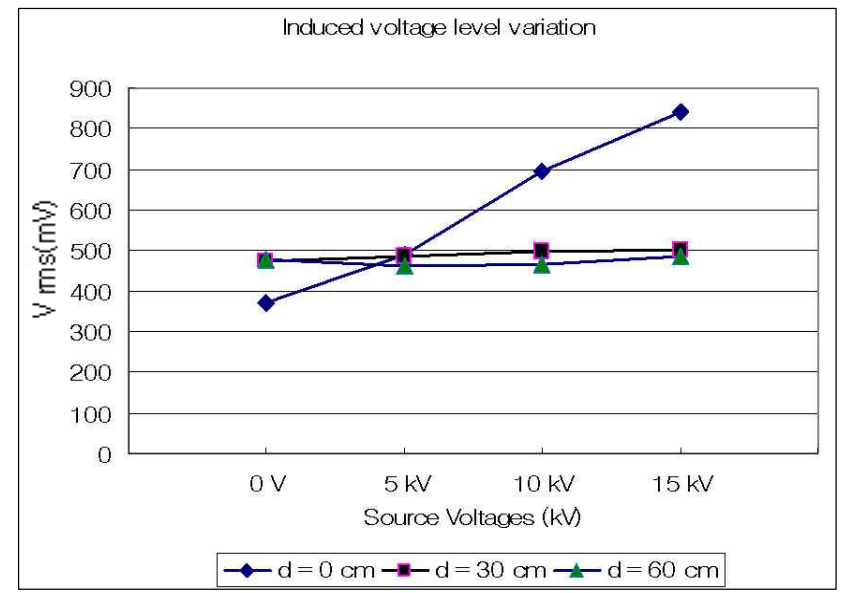

Fig. 14. Graphic analysis of induction(CH1).

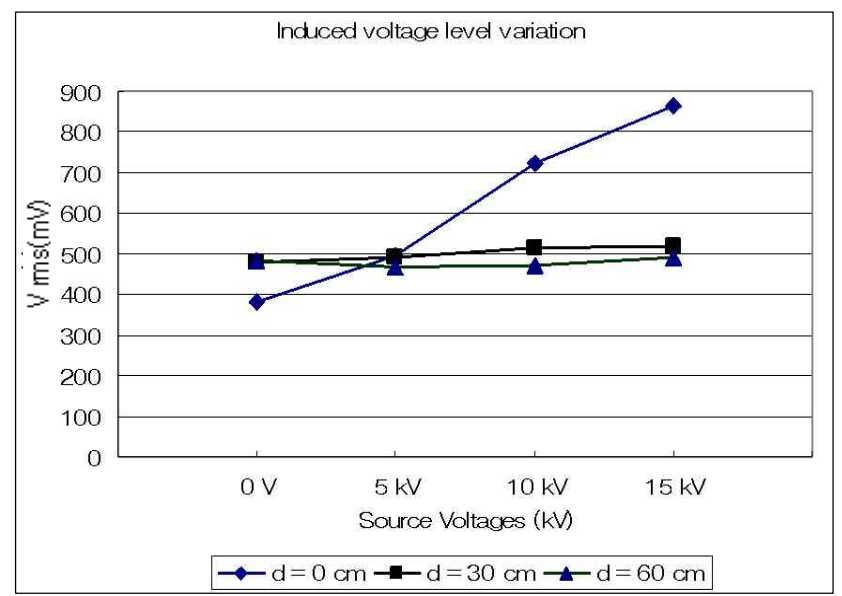

Fig. 15. Graphic analysis of induction $(\mathrm{CH} 2)$.
Table 4. Voltages induced by current $\operatorname{source}(d=0)$.

\begin{tabular}{|c|c|r|c|c|}
\hline \multirow{2}{*}{$\begin{array}{c}\text { Source } \\
\text { current } \\
(\mathrm{rms})\end{array}$} & \multicolumn{2}{|c|}{ CRO-CH 1 } & \multicolumn{2}{c|}{ CRO-CH 2 } \\
\cline { 2 - 5 } & $V_{p-p}(\mathrm{~V})$ & $V_{r m s}(\mathrm{mV})$ & $V_{p-p}(\mathrm{~V})$ & $V_{r m s}(\mathrm{mV})$ \\
\hline $0 \mathrm{~A}$ & 1.15 & 336 & 1.14 & 346 \\
\hline $30 \mathrm{~A}$ & 1.49 & 492 & 1.49 & 499 \\
\hline $60 \mathrm{~A}$ & 2.31 & 744 & 2.31 & 744 \\
\hline $90 \mathrm{~A}$ & 3.16 & 1,022 & 3.12 & 1,021 \\
\hline
\end{tabular}

values of $\mathrm{CH} 1$ and $\mathrm{CH} 2$ are not exactly the same, the changing trend is almost the same. From the graph, it is clear that only in the case of the separate distance $d=$ 0 is the induced voltage increasing proportionally. And in other d's, slight voltage is increased only at a highvoltage level above $10 \mathrm{kV}$.

\section{3-3 Characteristics of High-Current Source}

\section{3-3-1 0 m Separation Distance $(d=0)$}

The measured induced voltage is shown in the Table 4. The values of $\mathrm{CH} 1$ and $\mathrm{CH} 2$ are not exactly the same. And the induced voltage is increased by growing the current source level. Default voltage at a 0 source level exists. The CRO waveforms are shown in Fig.16 for the current source: 0 A; Fig. 17 for 30 A; Fig. 18 for $60 \mathrm{~A}$; Fig. 19 for 90 A.

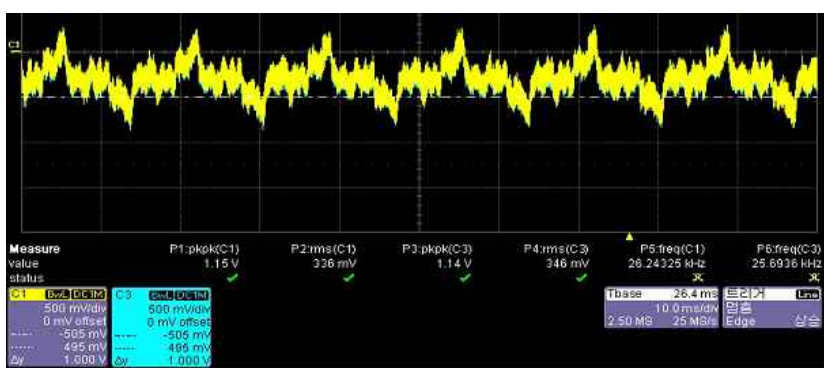

Fig. 16. Waveform for $0 \mathrm{~A}$ current $\operatorname{source}(500 \mathrm{mV} / \mathrm{div}$, and $10.0 \mathrm{~ms} / \mathrm{div})$.

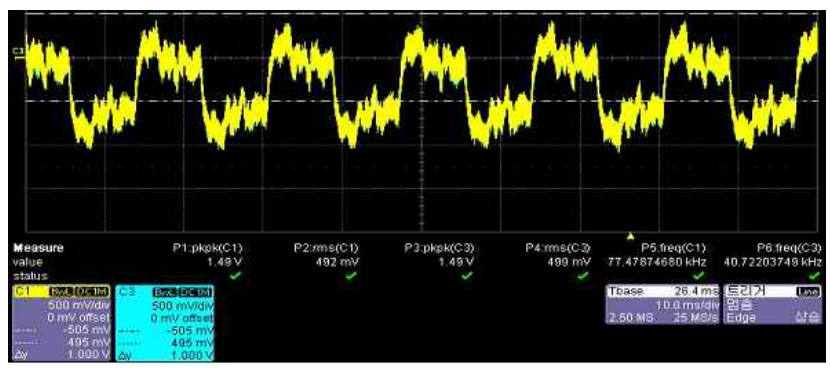

Fig. 17. Waveform for $30 \mathrm{~A}$ current source $(500 \mathrm{mV} / \mathrm{div}$, and $10.0 \mathrm{~ms} / \mathrm{div})$. 
LEE et al. : CHARACTERISTICS OF THE VOLTAGES BETWEEN THE COMMUNICATION LINES AND GROUND INDUCED BY‥

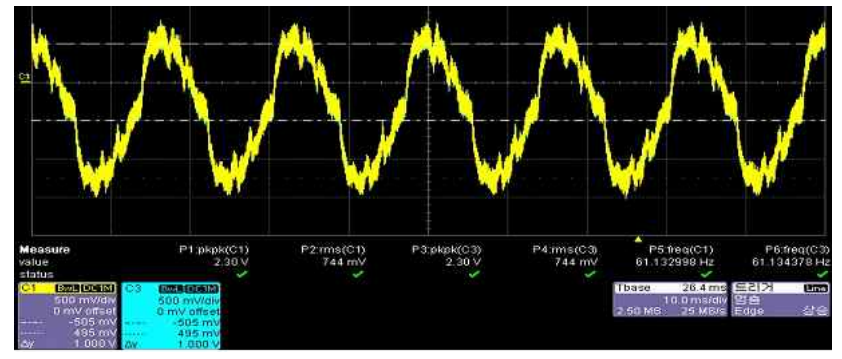

Fig. 18. Waveform for $60 \mathrm{~A}$ current source $(500 \mathrm{mV} / \mathrm{div}$, and $10.0 \mathrm{~ms} / \mathrm{div})$.

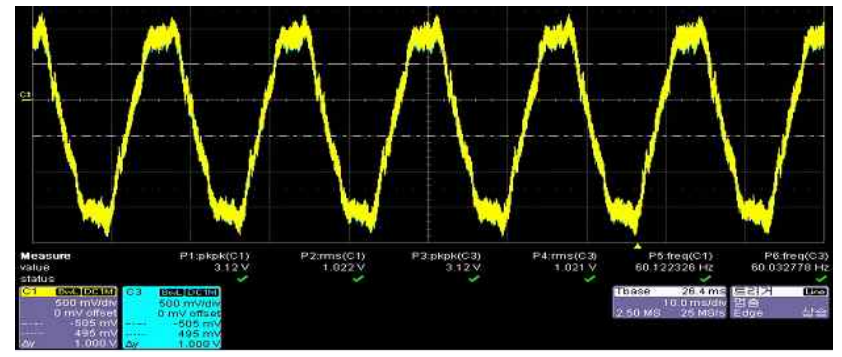

Fig. 19. Waveform for $90 \mathrm{~A}$ current source $(500 \mathrm{mV} / \mathrm{div}$, and $10.0 \mathrm{~ms} / \mathrm{div})$.

\section{3-3-2 $0.3 \mathrm{~m}$ Separation Distance $(d=0.3 \mathrm{~m})$}

The measured voltages at $d=0.3 \mathrm{~m}$ are shown in Table 5. The RMS value is slightly increasing, except the case of $0 \mathrm{~A}$, which is caused by an unknown exterior source while the peak-to-peak value tends to slightly decrease. The measured waveform for each case is shown in Fig. $20 \sim 23$.

\section{3-3-3 $0.6 \mathrm{~m}$ Separation Distance $(d=0.6 \mathrm{~m})$}

Interestingly, at this point, the induced voltage is rather decreased slightly. Each CRO waveform is shown in Fig. 24 27 .

\section{3-3-4 Analysis of Graph}

With respect to the high-current source, at the point of $d=0$, the induced voltage is proportionally increasing by the growing source levels. At the point of $d=0.3 \mathrm{~m}$,

Table 5 . Voltages induced at $d=0.3$ by current.

\begin{tabular}{|c|c|c|c|c|}
\hline \multirow{2}{*}{$\begin{array}{c}\text { Source } \\
\text { current } \\
(\mathrm{rms})\end{array}$} & \multicolumn{2}{|c|}{ CRO-CH 1 } & \multicolumn{2}{c|}{ CRO-CH 2 } \\
\cline { 2 - 5 } & $V_{p-p}(\mathrm{~V})$ & $V_{r m s}(\mathrm{mV})$ & $V_{p-p}(\mathrm{~V})$ & $V_{r m s}(\mathrm{mV})$ \\
\hline $0 \mathrm{~A}$ & 1.81 & 494 & 1.81 & 499 \\
\hline $30 \mathrm{~A}$ & 1.57 & 474 & 1.57 & 478 \\
\hline $60 \mathrm{~A}$ & 1.33 & 486 & 1.34 & 490 \\
\hline $90 \mathrm{~A}$ & 1.52 & 515 & 1.55 & 519 \\
\hline
\end{tabular}

Table 6. Measured voltage at $d=0.6 \mathrm{~m}$.

\begin{tabular}{|c|c|c|c|c|}
\hline \multirow{2}{*}{$\begin{array}{c}\text { Source } \\
\text { current } \\
(\mathrm{rms})\end{array}$} & \multicolumn{2}{|c|}{ CRO-CH 1 } & \multicolumn{2}{c|}{ CRO-CH 2 } \\
\cline { 2 - 5 } & $V_{p-p}(\mathrm{~V})$ & $V_{r m s}(\mathrm{mV})$ & $V_{p-p}(\mathrm{~V})$ & $V_{r m s}(\mathrm{mV})$ \\
\hline $0 \mathrm{~A}$ & 2.13 & 478 & 2.11 & 483 \\
\hline $30 \mathrm{~A}$ & 1.84 & 455 & 1.84 & 462 \\
\hline $60 \mathrm{~A}$ & 1.66 & 431 & 1.66 & 439 \\
\hline $90 \mathrm{~A}$ & 1.44 & 422 & 1.46 & 430 \\
\hline
\end{tabular}

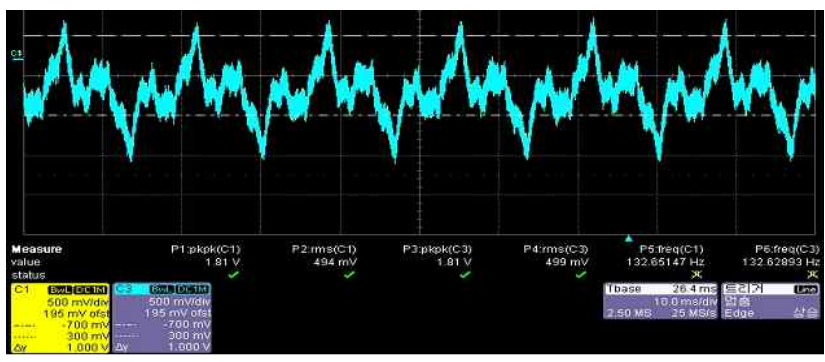

Fig. 20. The CRO waveform in $0 \mathrm{~A}(500 \mathrm{mV} / \mathrm{div}$, and 10.0 $\mathrm{ms} / \mathrm{div})$.

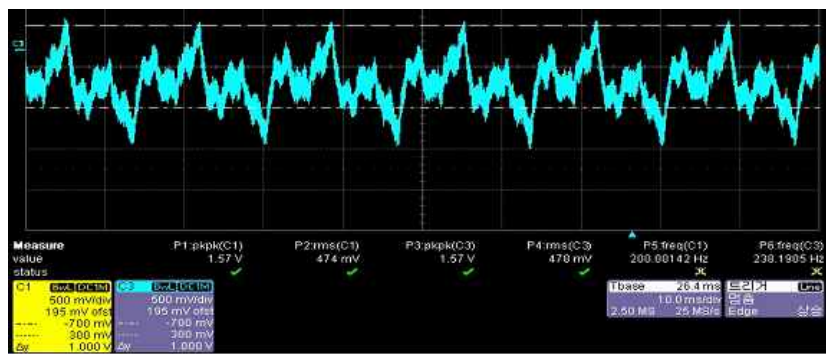

Fig. 21. The CRO waveform in $30 \mathrm{~A}(500 \mathrm{mV} / \mathrm{div}$, and 10.0 $\mathrm{ms} / \mathrm{div})$.

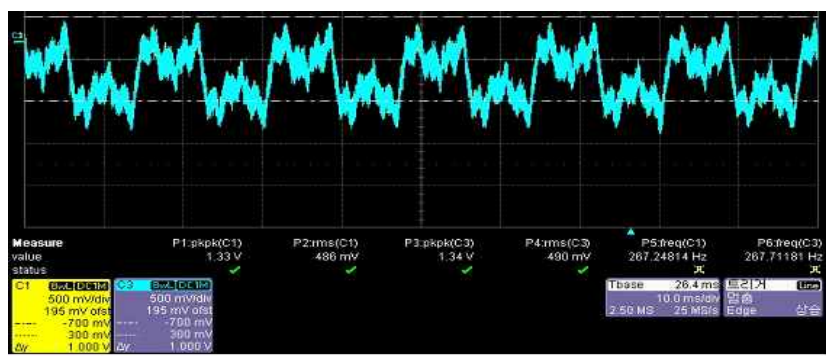

Fig. 22. The $\mathrm{CRO}$ waveform in $60 \mathrm{~A}(500 \mathrm{mV} / \mathrm{div}$, and $10.0 \mathrm{~ms} / \mathrm{div})$.

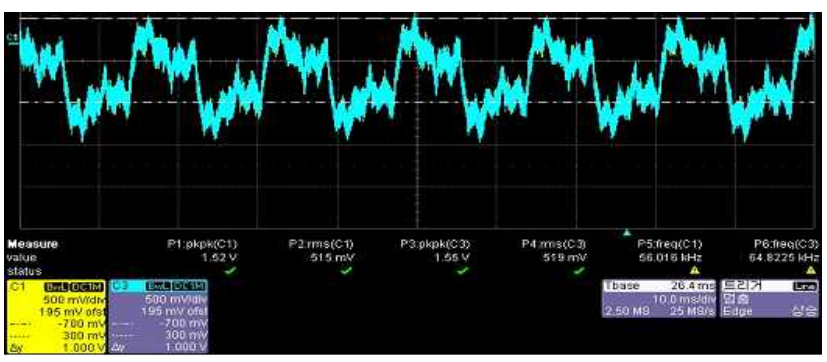

Fig. 23. The $\mathrm{CRO}$ waveform in $90 \mathrm{~A}(500 \mathrm{mV} / \mathrm{div}$, and $10.0 \mathrm{~ms} / \mathrm{div})$. 


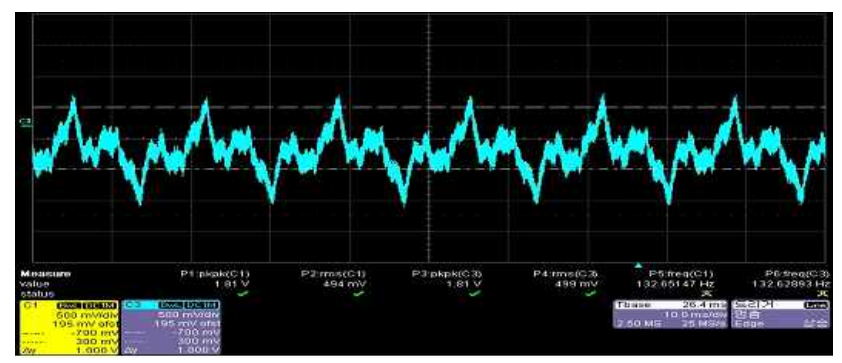

Fig. 24. Current source: $0 \mathrm{~A}(500 \mathrm{mV} / \mathrm{div}$, and $10.0 \mathrm{~ms} / \mathrm{div})$.

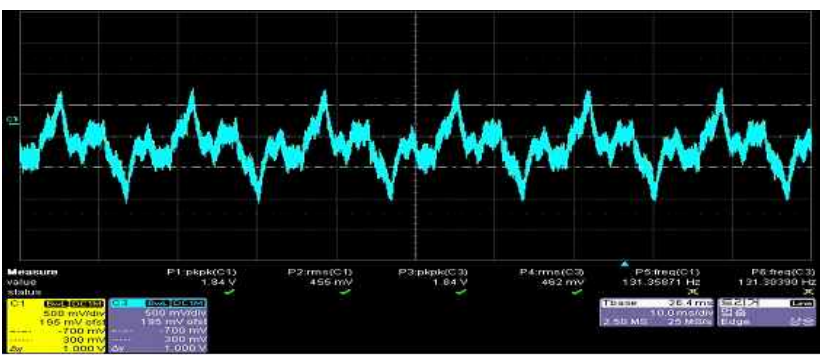

Fig. 25. Current source: $30 \mathrm{~A}(500 \mathrm{mV} / \mathrm{div}$, and $10.0 \mathrm{~ms} / \mathrm{div})$.

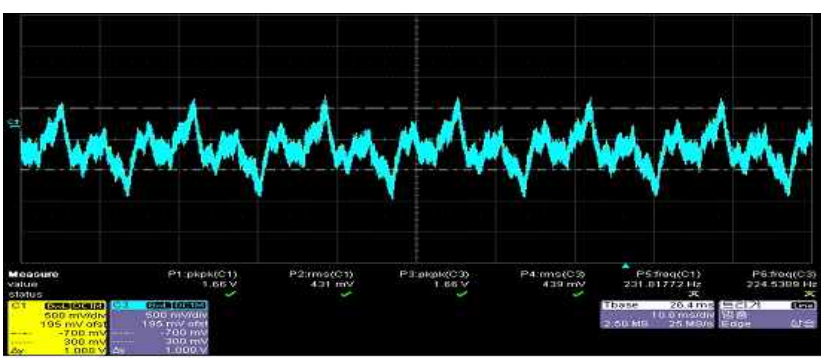

Fig. 26. Current source: $60 \mathrm{~A}(500 \mathrm{mV} / \mathrm{div}$, and $10.0 \mathrm{~ms} /$ div).

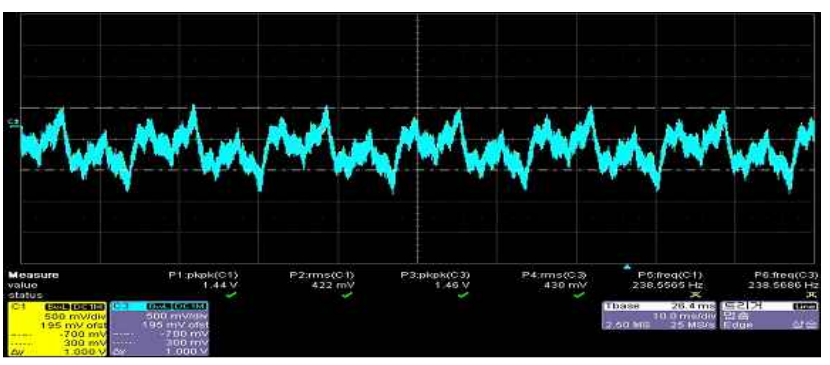

Fig. 27. Current source: $90 \mathrm{~A}(500 \mathrm{mV} / \mathrm{div}$, and $10.0 \mathrm{~ms} /$ div).

induced voltage is slightly increasing with the step currents. At the point of $0.6 \mathrm{~m}$, the induced voltage is rather slightly decreasing. For the $\mathrm{CH} 1$ and $\mathrm{CH} 2$ cases, the data values have little difference, but almost the same trend. Each channel curve is shown in Fig. 28 and Fig. 29.

\section{Conclusion}

That the voltage arising on telecommunication lines

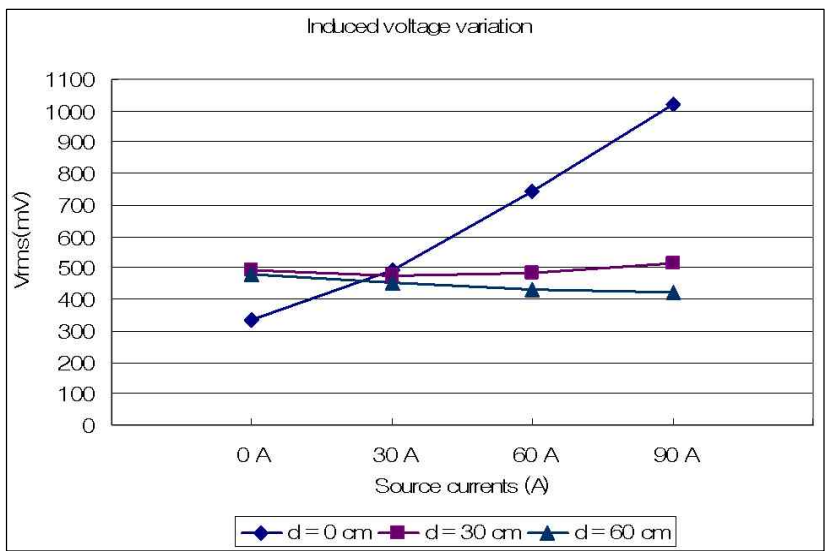

Fig. 28. Current source trend $(\mathrm{CH} 1)$.

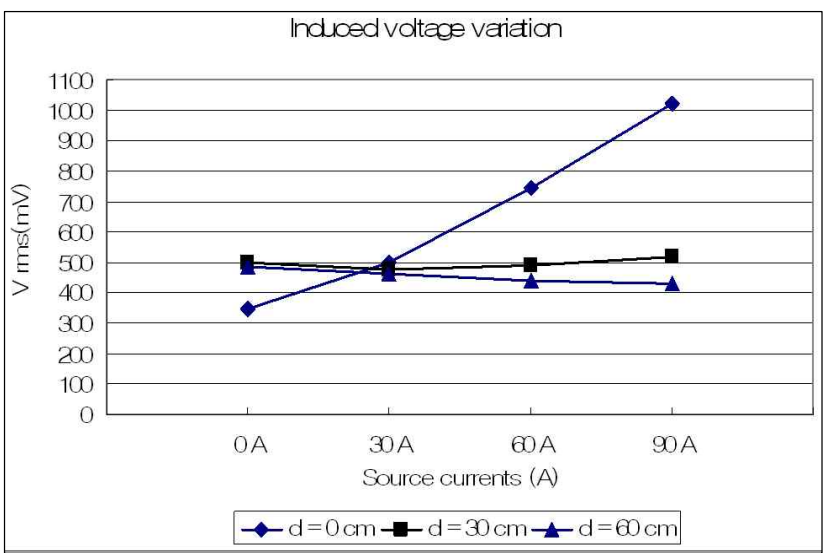

Fig. 29. Current source trend(CH2).

from power lines is by induction phenomenon has been confirmed by experiment in which an artificially made source generator was utilized. The induced voltage is generated by both an electric field from a high-voltage line and a magnetic field from a high-current source. It appears that the voltage induced by the magnetic source is $1.02 V_{r m s}$ (average of $\mathrm{CH} 1 \& 2$, at $d=0$, each maximum source level) which is greater than the voltage caused by the electric field.

\section{References}

[1] Korea Communications Commission, "Rules about technical regulation of telecommunication facilities", (1st ed.) Order of ROK President, no. 20664, Feb. 2008.

[2] Korea Communication Commission, "Technical regulation for the precise calculation method of induced voltages by power sources", Radio Research Agency's Publication, no. 2007-102, Dec. 2007.

[3] Korea Communication Commission, "The standardized testing method for the technical regulation of telecommunication facilities", Radio Research Agency's Publication, no. 2005-98. 


\section{Sangmu Lee}

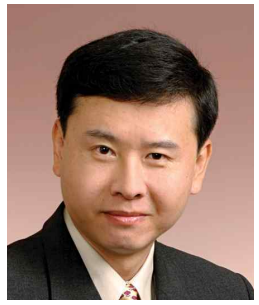

received the B.E. degree in electronics engineering from Dankook University in 1989, and the M.E. degree in computer engineering from Information and Communications University in 2000. $\mathrm{He}$ is working for Electronics and Telecommunications Research Institute since 1991. His main researching role is to make technical regulation related to electromagnetic induction and protective measure.

\section{Changsoo Eun}

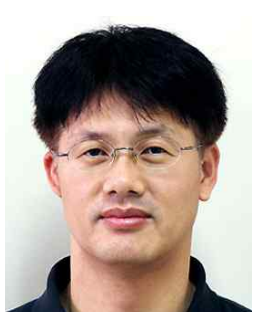

received his B.S. and M.S. degrees from Seoul National University in 1985 and 1987, respectively. He got his Ph.D. degree from the University of Texas at Austin in 1995. From 1987 to 1997, we worked for Daewoo Electronics Co. as a senior researcher. From 1997, he has been working with Chungnam National University as a faculty member. His research interest includes signal processing for telecommunications, RF circuits and applications.

\section{Yoon-Myoung Gimm}

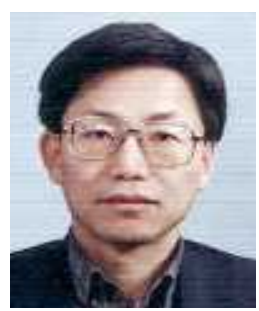

received the B.E. degree in electronics engineering from the Seoul National University in 1975 and the M.E. and Ph.D. degrees in electrical and electronics engineering from Korea Advanced Institute of Science and Technology in 1977 and 1990, respectively. Since 1980, he has been with the department of electronics engineering, Dankook University, Seoul, Korea, where he is now a professor in the school of electronics and computer engineering. He is also a CEO of EMF Safety Inc., since 2000. His research interests are the electromagnetic field measurements related with the biological effect.

\section{Pyung-Dong Cho}

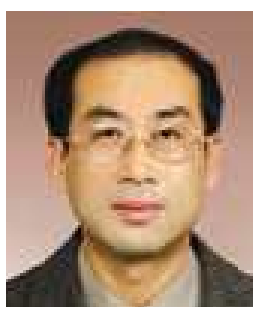

received the B.E. degree in electronics engineering from Yonsei University in 1980, and the M.E. and Ph.D. degrees in engineering of computer science from Chungnam National University in 1995 and 2003, respectively. Since 1979, he has been working in Electronics and Telecommunications Research Institute where he is now the leader of Technical Regulation Research Team. 